\title{
ВИЗНАЧЕННЯ ПРОГИНІВ НЕРОЗРІЗНИХ ЗАЛІЗОБЕТОННИХ БАЛОК ПРИ ПОВТОРНИХ НАВАНТАЖЕННЯХ
}

\author{
DETERMINATION OF DEFINITIONS OF UNINSTALLED \\ REINFORCED CONCRETE BEAMS AT REPEAT LOADS
}

\begin{abstract}
Савицький В.В., к.т.н., доцент Бабич В.Є., к.т.Н., доцент, (Національний університет водного господарства Tа природокористування, м. Рівне), Дробишинець С.Я., к.т.н., доцент (Луцький національний технічний університет)
\end{abstract}

Savitsky V.V., Ph.D. in Engineering, Associate Professor, Babych V.Ye, Ph.D. in Engineering, Associate Professor (National university of water management and nature resources use, Rivne), Drobyshynets S.Y., Ph.D. in Engineering, Associate Professor (Lutsk National Technical University)

Анотація. Викладена методика визначення прогинів нерозрізних залізобетонних балок при повторних навантаженнях з урахуванням зміни пружнопластичних характеристик бетону та наведені блок-схеми для використання методики на ПЕОМ.

Summary. According to the current design rules for reinforced concrete structures, the total deflection of the bending elements is defined as the sum of the deflection caused by the shear deformations, and the deflection caused by the deflections of the bending, taking into account the total curvature of the element in cross section from full load. For bending elements of long length, the deflection caused by shear deformations can be neglected. The curvature of the elements is determined by taking into account the coefficient that takes into account the work of loose concrete in the areas with cracks. The purpose of this work is to improve the method of determining deflections of nonintersecting beams at repeated short-term loads taking into account the change of modulus of elastic plasticity of concrete. When determining deflections of nonintersecting beams at repeated loads, it is necessary to take into account the change in the length of the sign of the bending moment, the transverse force, the curvature of the axis of the beam and changes in the modulus of elasticity of the concrete due to repeated loads. Standards recommend that statically indeterminate designs be calculated taking into account the redistribution of effort. Since the plot of moments and transverse forces from a single load are linear, then the method of calculation of deflections can be used method Vereshchagin AN, breaking the beam into areas within which the stiffness is taken as average. The modulus of elasticity of concrete is determined by its change due to repeated loads. The advanced technique of determination of deflections of non-cutting beams from bending and shear deformations takes into account the change of elasticplastic characteristics of concrete due to the action of repeated loads. The developed 
flowcharts can be used to determine the deflections of non-intersecting beams under the action of repeated loads.

Ключові слова: бетон, арматура, прогин, нерозрізний, повторний.

Keywords: concrete, armature, deflection, indissoluble, repeated.

Стан питання. Згідно 3 чинними нормами проектування залізобетонних конструкцій повний прогин $f$ згинальних елементів визначається за формулою [1]:

$$
f=f_{m}+f_{q}=\int_{0}^{l} \bar{M}(x)\left(\frac{1}{r}\right)(x) d x+\int_{0}^{l} \bar{Q}(x) \gamma(x) \partial x,
$$

де $f_{m}$ - прогин, обумовлений деформаціями згину;

$f_{q}$ - прогин, обумовлений деформаціями зсуву;

$\bar{M}(x)$ і $\bar{Q}(x)$ - згинальний момент і поперечна сила в перерізі $x$ від дії одиничної сили, прикладеної в напрямку переміщення, яке визначається, по довжині прольоту в тому ж перерізі $x$;

$\left(\frac{1}{r}\right)(x)$ - повна кривизна елемента в перерізі $x$ від зовнішнього навантаження;

$\gamma(x)$ - деформація зсуву, яка визначається за формулою:

$$
\gamma(x)=\frac{1,5 Q(x) \varphi_{b 2}}{G b h_{0}} \varphi_{c r c}(x),
$$

$\mathrm{Q}(x)$ - поперечна сила в перерізі $x$ від дії зовнішнього навантаження;

$\varphi_{b 2}$ - коефіцієнт, який враховує тривалу повзучість бетону (при короткочасній дії навантаження $\left.\varphi_{b 2}=1,0\right)$;

$G$ - модуль зсуву бетону $\left(\mathrm{G}=0,4 E_{b}\right) ; E_{b}$ - початковий модуль пружності бетону; $b, h_{0}$ - ширина і робоча висота перерізу елемента;

$\varphi_{c r c}(x)$ - коефіцієнт, який враховує вплив тріщин на деформації зсуву і визначається за формулою:

$$
\varphi_{c r c}(x)=\frac{3 E_{b} I_{r e d}}{M(x)}\left(\frac{1}{r}\right)(x)
$$

$I_{\text {red }}$ - момент інерції приведеного перерізу; 
$l$ - розрахунковий проліт балки.

Для згинальних елементів при $l / h \geq 10$ значення $f_{q}$ можна не обчислювати, тобто приймати $f_{q}=0$. Кривизну елементів на ділянках 3 тріщинами, обумовлену згином, для елементів без попереднього напружування арматури визначають за формулою:

$$
\left(\frac{1}{r}\right)(x)=\frac{M(x) \psi_{s}(x)}{z(x) A_{s} E_{s}\left(h_{0}-x\right)},
$$

де $z(x)$ - віддаль від центра ваги розтягнутої арматури до точки прикладання зусилля в стиснутій зоні бетону в перерізі з тріщиною;

$A_{s}$ - площа розтягнутої арматури;

$E_{s}$ - модуль пружності арматури;

$x$ - висота стиснутої зони бетону в перерізах;

$\psi_{s}(x)$ - коефіцієнт, який враховує роботу розтягнутого бетону на ділянках з тріщинами.

Для згинальних елементів постійного перерізу без попереднього напружування арматури на ділянках, де згинальний момент не міняє знаку, допускається кривизну обчислювати для найбільш напруженого перерізу, а для інших перерізів цієї ділянки вважати ії зміну пропорційно значенням згинальних моментів.

Аналіз наведених вище формул показує, що вони справедливі при дії короткочасних або тривалих навантажень. Відомо, що більшість конструкцій експлуатується при дії повторних навантажень [2, 3], що не враховується чинними нормами. Крім того, повторні навантаження можуть впливати на зміну пружнопластичних характеристик бетону, що також залишається поза увагою нормативних документів.

Метою роботи $є$ удосконалення методики визначення прогинів нерозрізних балок при повторних короткочасних навантаженнях 3 урахуванням зміни модуля пружнопластичності бетону.

Визначення прогинів. При визначенні прогинів нерозрізних балок при повторних навантаженнях необхідно врахувати зміну по довжині знаку згинального моменту, поперечної сили, кривизни осі балки та зміни модуля пружнопластичності бетону внаслідок повторних навантажень.

Розглянемо двопролітну нерозрізну балку прямокутного профілю, завантажену зосередженими силами $P$, що прикладаються повторно (рис. $1 a$ ). Згідно 3 розрахунком за пружною стадією роботи балки при $\alpha=0,57$ і $\beta=0,43$ значення пролітного моменту складає $M_{s p}=0,136 P l$, а опорного $M_{\text {sup }}=0,192 P l$ (рис. 16). 


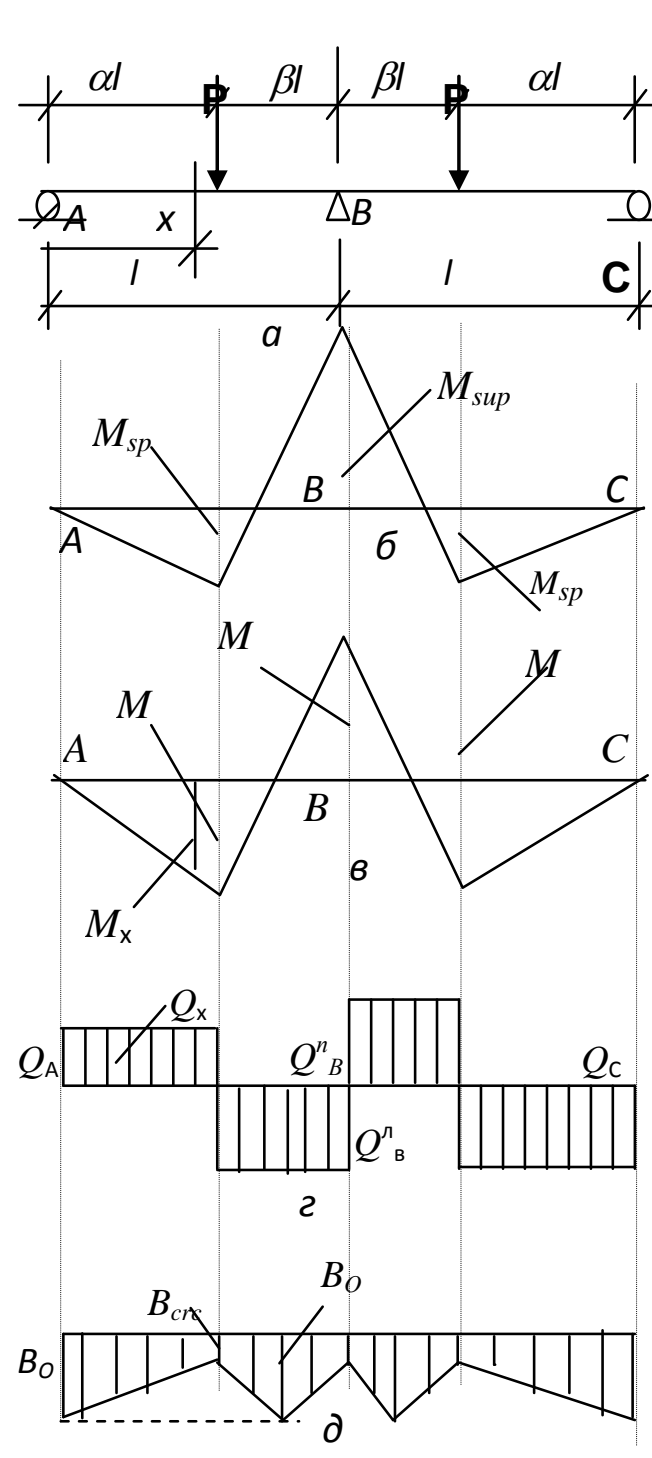

Рис. 1. Розрахункова схема двопролітної нерозрізної балки $(a)$, епюра моментів в пружній стадії (б), те саме - 3 урахуванням перерозподілу зусиль (в), поперечних сил (2), зміна жорсткості (d).

Норми рекомендують статично невизначені конструкції розраховувати з урахуванням перерозподілу зусиль. Для цього випадку за умови рівноміцності опорних і пролітних перерізів моменти будуть одинаковими, тобто $M=M_{\text {sup }}=M_{s p}=0,155 P l$ (рис.1в). Ординати епюри поперечних сил будуть дорівнювати $Q_{A}=0,275 P ; \quad Q_{B}{ }^{n}=$ $=0,725 P$ (рис. 12). Оскільки балка розглядається без попереднього напружування арматури, в іiі розтягнутих зонах будуть виникати тріщини, максимальна ширина розкриття яких буде над опорою та під силами в прольотах. Певно в цих місцях буде мінімальна жорсткість перерізів $\mathrm{B}_{\mathrm{crc}}$, а в місцях, де $\mathrm{M}=0$, жорсткість буде максимальною $\mathrm{B}_{\mathrm{O}}$ (рис. 1d). Зміну жорсткості вздовж балки приймемо пропорціонально діючим згинальним моментам (рис1д).

Жорсткість $B_{0}$ в перерізах, де $M=0, \quad$ визначаємо за формулою

$$
B_{0}=E_{b} I_{\text {red }},
$$

де $I_{\text {red }}$ - момент інерції приведеного перерізу.

Мінімальну жорсткість балки в перерізах, де діють максимальні моменти на $i$-му 
циклі навантаження, визначимо за формулою:

$$
B_{c r c, i}(x)=z_{i}(x) A_{s} E_{s}\left(h_{0}-x_{i}(x)\right) \frac{1}{\psi_{s i}(x)},
$$

де $B_{c r c, i}$ - мінімальна жорсткість балки на $i$-му циклі навантаження;

$x_{i}(x), z_{i}(x), \psi_{s i}(x)$ - те саме, що і у формулі (4), але на і-му циклі навантаження.

Для елементів прямокутного профілю значення $z_{i}(x)$ можна визначити за формулою [1]:

$$
z_{i}(x)=h_{0}-x_{i}(x) / 3
$$

а висоту стиснутої зони бетону:

$$
\begin{gathered}
x_{i}(x)=\varphi_{\xi i}(x) h_{0}, \\
\text { де } \varphi_{\xi i}(x)=\beta_{i}(x)\left(\sqrt{1+2 / \beta_{i}(x)}-1\right) ; \\
\beta_{i}(x)=\alpha_{i}(x) \mu \frac{\psi_{b} \varphi_{b 2}}{\psi_{s i} \varphi_{b 1}} ; \\
\alpha_{i}(x)=E_{s} / E_{b, c y c, i} ; \mu=A_{s} /\left(b h_{0}\right) ;
\end{gathered}
$$

$E_{b, c y c, i}$ - модуль пружнопластичності бетону при повторних навантаженнях на $i$-му циклі;

$\varphi_{b}{ }^{-}$коефіцієнт, що враховує нерівномірність розподілення деформацій крайнього стиснутого волокна бетону на ділянках з тріщинами (для важкого бетону $\varphi_{b}=0,9$ ).

Коефіцієнт $\psi_{s i}(x)$ можна знайти за формулою:

$$
\psi_{s i}(x)=1,25-\varphi_{l s} \varphi_{m i}(x),
$$

де $\varphi_{l s}=1,0$ - при нетривалій дії навантаження для конструкцій зі стержневою арматурою [1];

$$
\varphi_{m i}(x)=\frac{R_{b t, s e r} W_{p l}}{M_{i}(x)} \leq 1,0,
$$

де $R_{b r, s e r}$ - нормативний опір бетону розтяганню; 
$W_{p l}$ - момент опору приведеного перерізу для крайнього розтягнутого волокна з урахуванням непружних деформацій бетону (для прямокутних перерізів можна прийняти $W_{p l}=1,75 W_{r e d}, W_{r e d}$ - момент опору приведеного перерізу ).

Значення модуля пружнопластичності бетону з урахуванням його зміни внаслідок дії повторних навантажень $E_{b, c y c, i}$ можна визначити за формулою, яка має вигляд, подібний як в роботі [4],

$$
E_{b, c y c, i}=E_{b, 0, c y c, i}\left(1-\lambda_{R, c y c, i} \eta_{c y c, i}\right),
$$

де $E_{b, 0, c y c, i}$ - модуль пружнопластичності бетону при $\sigma_{b, c y c}=0$ на $i$ му циклі навантаження;

$\lambda_{R, c y c, i}$ - граничний коефіцієнт пластичності бетону;

$\eta_{c y c, i}$ - рівень навантаження на $i$-му циклі.

Виходячи $з$ наведеного, прогин від деформації згину на $i$-му циклі повторних навантажень можна визначити за трансформованою формулою (1) у вигляді:

$$
f_{m i}=\int_{0}^{l} \bar{M}(x)\left(\frac{M(x)}{B_{c r c, i}(x)}\right) \partial x .
$$

Для визначення прогинів від деформацій зсуву для випадку повторних навантажень формулу (2) можна трансформувати у вигляд

$$
\gamma_{i}(x)=\frac{1,5 Q_{i}(x) \varphi_{b 2}}{G_{c y c, i} b h_{0}} * \frac{3 E_{b, c y c, i} I_{r e d}}{B_{c r c, i}(x)},
$$

де $G_{c y c, i}=0,4 E_{b, c y c, i}$;

$B_{c r c, i}$ - визначається за формулою (6).

3 уразуванням (16) прогин від деформацій зсуву для $i$-го циклу повного навантаження можна визначити за формулою:

$$
f_{q i}=\int_{0}^{l} \bar{Q}(x) \gamma_{i}(x) d x .
$$

Блок-схеми для визначення $f_{m i}$ i $f_{q i}$ представлені на рис. 2 і рис. 3.

Оскільки епюри $\bar{M}(x)$ і $\bar{Q}(x)$ від одиничного навантаження мають лінійний характер, то для обчислення інтегралів (15) і (17) можна використати метод Верещагіна А.Н., розбиваючи балку на ділянки, в межах яких жорсткість приймати середньою. 


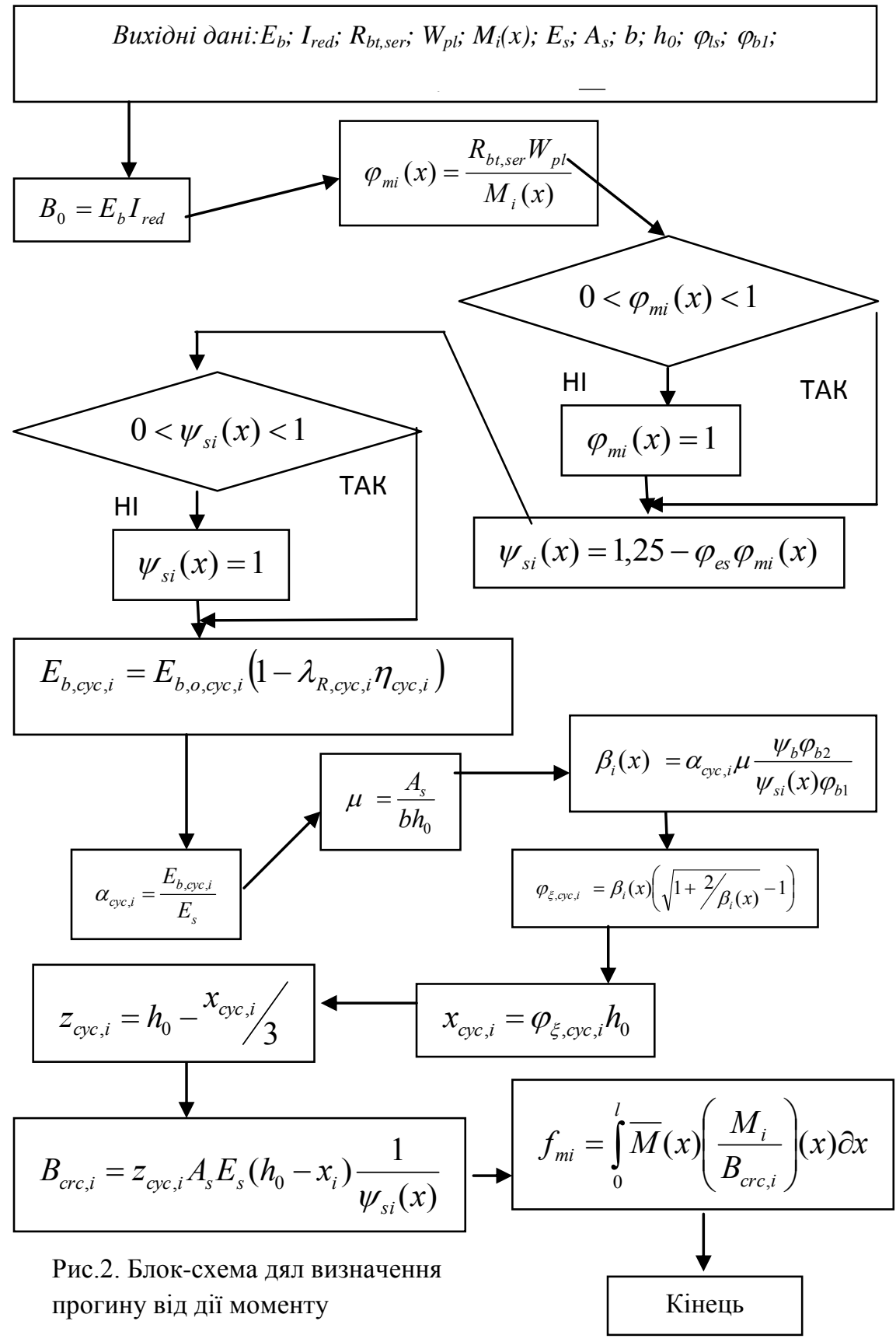


Вихідні дані: $E_{b} ; I_{r e d} ; R_{b t, s e r} ; W_{p l} ; E_{s} ; A_{s} ; b ; h_{0} ; \varphi_{l s} ; \varphi_{b l}$;

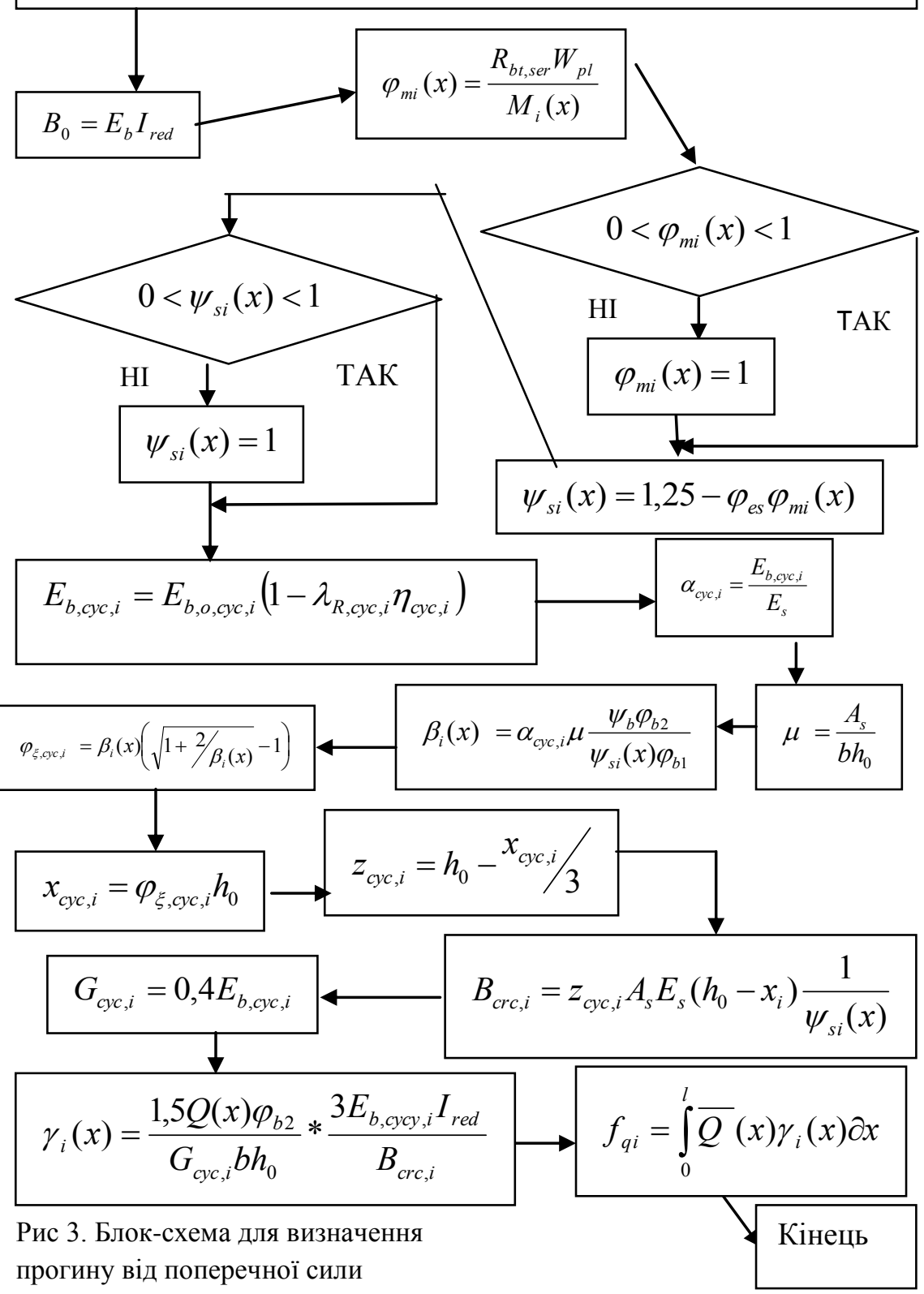




\section{Висновки}

1. Наведена удосконалена методика визначення прогинів нерозрізних балок від деформацій згину і зсуву враховує зміну пружнопластичних характеристик бетону внаслідок дії повторних навантажень.

2. Розроблені блок-схеми можуть бути використані для визначення прогинів нерозрізних балок при дії повторних навантажень.

\section{References}

1. DSTU B V.2.6-156:2010. Betonni ta zalizobetonni konstruktsiyi z vazhoho betonu. Pravyla proektuvannya - Kyyiv, Minrehionbud, 2011.

2. Barashykov A.YA. Raschet zhelezobetonnykh konstruktsyy na deystvye dlytel'nykh peremennykh nahruzok. - Kyev: Budivel'nyk, 1977. - 156s.

3. Babych YE.M., Krus' YU.O. Betonni ta zalizobetonni elementy v umovakh malotsyklovykh navantazhen'. - Rivne: Vyd-vo RDTU, 1999. - 119s.

4. Babych YE.M., Il'chuk N.I. Mitsnist' i deformatyvnist' vazhkoho betonu pry malotsyklovomu stysnenni / Resursoekonomni materialy, konstruktsiyi, budivli ta sporudy: Zbirnyknaukovykh prats'. - Rivne: Vyd-vo UDUVHP, 2003. - Vypusk 9. - s. 116-123.

\section{Список використаної літератури}

1. ДСТУ Б В.2.6-156:2010. Бетонні та залізобетонні конструкції з важого бетону. Правила проектування - Київ, Мінрегіонбуд, 2011.

2. Барашиков А.Я. Расчет железобетонных конструкций на действие длительных переменных нагрузок. - Киев: Будівельник, 1977. - 156с.

3. Бабич Є.М., Крусь Ю.О. Бетонні та залізобетонні елементи в умовах малоциклових навантажень. - Рівне: Вид-во РДТУ, 1999. - 119с.

4. Бабич С.М., Ільчук Н.І. Міцність і деформативність важкого бетону при малоцикловому стисненні / Ресурсоекономні матеріали, конструкції, будівлі та споруди: Збірникнаукових праць. - Рівне: Вид-во УДУВГП, 2003. - Випуск 9. - с. 116-123. 